\title{
SOSIALISASI DAN PELATIHAN PENGOLAHAN SAMPAH MENJADI PUPUK KOMPOS SEBAGAI UPAYA PENINGKATAN PENGETAHUAN AKAN MANFAAT PENGELOLAAN SAMPAH DI PASAR MADRASAH
}

\author{
Tri Yuhanah ${ }^{1}$, Budi Wicaksono $^{2}$, Devita Mayasari ${ }^{3}$, Dicki Dian Purnama $^{4}$, Tommy Iduwin $^{5}$ \\ ${ }^{1,2,3}$ Sekolah Tinggi Teknik PLN, Jl. Lingkar Luar Barat, Duri Kosambi, Cengkareng, Jakarta Barat \\ Program Studi Teknik Sipil \\ e-mail:
}

\begin{abstract}
Abstrak
Adanya Pasar Madrasah sangat membantu perekonomian serta memberikan kemudahan kepada warga sekitar RT 007 dan RT 012/RW 02 Kelurahan Duri Kosambi, Kecamatan Cengkareng, Jakarta Barat dalam berbelanja kebutuhan sehari-hari. Namun dengan adanya pasar tersebut timbul masalah yang hingga saat ini masih belum mendapatkan perhatian serius dari para pedagang dan pembeli. Masalah tersebut yaitu munculnya sampah-sampah yang dapat mencemari lingkungan dan menyebabkan timbulnya wabah penyakit. Padahal sampah-sampah tersebut dapat dimanfaatkan untuk menjadi produk-produk yang bermanfaat seperti menjadi pupuk kompos serta barang kerajinan yang bernilai ekonomi. Kegiatan sosialisasi dan pelatihan dilakukan dengan metode penyuluhan dan demonstrasi pembuatan pupuk kompos oleh tim dan warga masyarakat sekitar. Narasumber berasal dari Jurusan Teknik Sipil, warga masyarakat di wilayah RT 007 dan RT 012/RW 02 Kelurahan Duri Kosambi,Kecamatan Cengkareng, Jakarta Barat, serta dukungan perangkat kelurahan, $R T$ dan $R W$, serta tokoh masyarakat setempat. Dana pendukung dari institusi STT-PLN merupakan aspek penting terselenggaranya kegiatan PKM ini. Manfaat yang dapat diperoleh peserta dari kegiatan PKM ini antara lain warga masyarakat dapat mengolah sampah organik menjadi pupuk kompos serta meningkatnya pengetahuan dalam pengelolaan dan pengolahan sampah sehingga lingkungan menjadi lebih bersih dan nyaman serta bisa meningkatkan perekonomian.
\end{abstract}

Kata kunci: pasar, sampah, pupuk kompos

\begin{abstract}
The Madrasa Market is very helpful to the economy and provides convenience to residents around RT 007 and RT 012 / RW 02 in Duri Kosambi Village, Cengkareng District, West Jakarta in shopping for daily necessities. But with the existence of this market a problem arises that until now still has not received serious attention from traders and buyers. The problem is the emergence of garbage that can pollute the environment and cause epidemics. Even though these wastes can be used as useful products such as compost and economic value handicrafts. Dissemination and training activities were carried out with methods of counseling and demonstration of making compost by the
\end{abstract}


team and residents of the surrounding community. The speakers came from the Civil Engineering Department, community members in the RT 007 and RT 012 / RW 02 areas of Duri Kosambi Village, Cengkareng District, West Jakarta, as well as the support of the villager, RT and RW, as well as local community leaders. Supporting funds from STT-PLN institutions are important aspects of the implementation of this PKM activity. The benefits that can be obtained by participants from the PKM activities include community members can process organic waste into compost fertilizer and increase knowledge in waste management and processing so that the environment becomes cleaner and more comfortable and can improve the economy.

Keywords: markets, garbage, compost

\section{PENDAHULUAN}

Untuk mencapai kondisi masyarakat yang hidup sehat dan sejahtera di masa yang akan datang, akan sangat diperlukan adanya lingkungan permukiman yang sehat. Dari aspek persampahan, maka kata sehat akan berarti sebagai kondisi yang akan dapat dicapai bila sampah dapat dikelola secara baik sehingga bersih dari lingkungan permukiman dimana manusia beraktifitas di dalamnya ${ }^{[1]}$.

Sampah merupakan sisa kegiatan sehari hari manusia atau proses alam yang berbentuk padat atau semi padat berupa zat organik atau anorganik bersifat dapat terurai atau tidak dapat terurai yang dianggap sudah tidak berguna lagi dan dibuang ke lingkungan ${ }^{[2]}$.

Sampah sering kali menjadi fenomena masalah yang belum bisa diselesaikan secara efektif. Berbagai strategi sudah dilakukan baik oleh pemerintah, maupun lembaga dan para pegiat lainnya. Kesadaran masyarakat yang masih rendah untuk mengolah sampah, menjadi salah satu persoalan besar yang selalu menjadi alasan munculnya dampak dari sampah. Sementara itu, sampah baru selalu dihasilkan oleh masyarakat dalam kehidupan kesehariannya.

Di beberapa daerah yang sudah menginisiasi pengolahan sampah melalui TPA, dan juga pembuatan "Bank Sampah" yang dikelola oleh masyarakat di lingkungannya. Masih sering kali menimbulkan persoalan dalam proses pengolahan sampah, karena kurangnya kesadaran masyarakat untuk memisahkan sampah organik dan sampah anorganik. Sampah organik dan sampah anorganik harus dipisahkan karena proses pengolahannya yang berbeda.

Sampah anorganik yang biasanya dalam bentuk plastik, kaleng, karet, seng, logam, besi dan bahan lainnya, bisa didaur ulang untuk menjadi barang baru lagi. Bahkan di beberapa daerah sudah ada yang bisa menghasilkan barang kerajinan yang dibuat dari bahan-bahan sampah anorganik. Sementara untuk sampah organik seperti daun gugur, sampah dari sisa pertanian, sampah dari sayuran dapur, dan jenis sampah organik lainnya. Bisa diolah sendiri oleh masyarakat menjadi pupuk kompos, yang tentunya akan memberikan manfaat yang lebih kepada masyarakat.

Selain bisa digunakan sendiri untuk pertanian atau pemeliharaan tanaman oleh masyarakat. Pupuk kompos juga memiliki nilai ekonomis dan peluang usaha yang bisa dikembangkan. Sebuah nilai tambah yang bisa didapatkan dari mengolah sampah organik menjadi pupuk 
kompos. Pupuk kompos yang dibuat dari bahan sampah organik juga bisa digunakan untuk perawatan tanaman dalam sistem pertanian organik ${ }^{[3]}$.

Pelaksanakan tridarma perguruan tinggi untuk dosen bukan hanya dalam kegiatan pendidikan dan penelitian saja, tetapi juga melakukan pengabdian pada masyarakat. Pengabdian pada masyarakat dipandang perlu dilakukan sebagai sarana pengaplikasian ilmu yang dapat bermanfaat bagi masyarakat.

Upaya pengabdian pada masyarakat bagi dosen-dosen di Jurusan Teknik Sipil STT-PLN yang saat ini diperlukan oleh warga adalah pengelolaan dan pengolahan sampah organik menjadi kompos dengan metode sederhana. Tujuannya meningkatkan nilai manfaat sampah menjadi bahan yang lebih berguna dan mengurangi pencemaran lingkungan. Oleh karena itu dipandang perlu bagi dosen-dosen Jurusan Teknik Sipil STT-PLN untuk melakukan pelatihan dan sosialisasi bagi warga masyarakat lingkungan RT 007 dan RT 012/RW 02 Kelurahan Duri Kosambi, Kecamatan Cengkareng, Jakarta Barat tentang pengelolaan dan pengolahan sampah organik menjadi kompos dengan cara sederhana yang mudah dipahami dan diterapkan oleh masyarakatyang dikemas dalam paket pengabdian masyarakat oleh Tim Dosen Jurusan Teknik Sipil STT-PLN.

Adapun tujuan dilaksanakannya kegiatan pengadian pada masyarakat adalah sebagai berikut:

1) Sosialisasi tentang pentingnya kebersihan lingkungan salah satunya dengan mengajak membuang sampah pada tempatnya,

2) Menjelaskan jenis-jenis sampah agar ketika peserta membuang sampah dapat dipilah terlebih dahulu,

3) Memberi nilai tambah pada sampah organik agar berdaya guna, salah satunya dengan diolah menjadi pupuk kompos,

4) Menjelaskan dan mendampingi masyarakat dalamproses mengolah sampah organik menjadi pupuk kompos di lokasi mitra kegiatan.

Kegiatan program kemitraan masyarakat ini diharapkan dapat meningkatkan kepedulian masyarakat sekitar pasar untuk bersama-sama menjaga kebersihan lingkungan wilayah RT 007 dan RT 012/RW 02 Kelurahan Duri Kosambi, Kecamatan Cengkareng, Jakarta Barat. Kegiatan ini juga diharapkan dapat meningkatkan pengetahuan masyarakat akan manfaat pengelolaan sampah di Pasar Madrasah dan mampu mengelola sampah tersebut menjadi pupuk kompos.

\section{METODE}

Kegiatan PKM ini dimulai dengan identifikasi permasalahan yang timbul di masyarakat sekitar kampus STT-PLN. Berdasarkan hasil pengamatan visual tampak adanya tumpukan sampah di Pasar Madrsah di wilayah RT 007 dan RT 012/RW 02 Kelurahan Duri Kosambi, Kecamatan Cengkareng, Jakarta Barat. Kemudian dilanjutkan dengan penyusunan 
rancangan tahapan kegiatan. Adapun kegiatan pengabdian kepada masyarakat terdiri atas beberapa tahap yaitu:

1) Survei ke lokasi mitra wilayah RT 007 dan RT 012/RW 02 Kelurahan Duri Kosambi, Kecamatan Cengkareng, Jakarta Barat untuk menggali lebih lanjut permasalahan dan kebutuhan mitra.

2) Merencanakan kegiatan pengabdian pada masyarakat dalam upaya untuk memperbaiki masalah terkait pengelolaan sampah organiksesuai kebutuhan mitra.

3) Melaksanakan kegiatan pengabdian pada masyarakat sesuai jadwal yang disepakati antara tim dan mitra.

4) Melakukan pengamatan dan observasi untuk mengetahui dampak/hasil yang tampak saat pelaksanaan kegiatan.

5) Mengevaluasi hasil kegiatan pengabdian pada masyarakat yang dilaksanakan.

6) Membuat laporan pertanggungjawaban pelaksanaan kegiatan pengabdian pada masyarakat.

Pengabdian kepada masyarakat ini dilaksanakan di wilayah RT 007 dan RT 012/RW 02 Kelurahan Duri Kosambi, Kecamatan Cengkareng, Jakarta Barat. Kegiatan ini akan dilaksanakan pada bulan Oktober 2017 s.d Maret 2018. Adapun luaran yang diharapkan dari kegiatan ini adalah:

1) Warga masyarakat wilayah RT 007 dan RT 012/RW 02 Kelurahan Duri Kosambi, Kecamatan Cengkareng, Jakarta Barat mengetahui perbedaan sampah organik dan anorganik serta mampu memilahnya.

2) Peningkatan daya guna sampah. Sampah organik dari sisa kegiatan pasar yang awalnya tidak berdaya guna (dibuang), menjadi memiliki nilai tambah setelah dijadikan pupuk kompos.

3) Terciptanya lingkungan yang lebih bersih dan sehat di wilayah RT 007 dan RT 012/RW 02 Kelurahan Duri Kosambi, Kecamatan Cengkareng, Jakarta Barat.

\section{HASIL DAN PEMBAHASAN}

Sebelum diadakan kegiatan penyuluhan pengolahan sampah organik menjadi pupuk kompos, sampah sisa kegiatan pasar menumpuk di sekitar lokasi pasar. Hal ini menimbulkan beberapa permasalahan, diantaranya lingkungan yang kotor, bau tidak sedap, dan banyak kuman penyakit bertebaran.

Namun setelah kegiatan penyuluhan berlangsung, warga di sekitar Pasar Madrasah mulai memiliki kesadaran untuk membuang sampah pada tempatnya. Sampah yang dibuang tersebut sebelumnya dipilah berdasarkan jenisnya, yaitu sampah organik dan anorganik. Selanjutnya, warga pun mendapat pengetahuan baru bahwa sampah organik sisa kegiatan 
pasar tersebut dapat diolah menjadi pupuk kompos dalam skala kecil dan dengan teknologi sederhana, sehingga tidak terbuang sia-sia.

Kegiatan pengabdian kepada masyarakat ini diawali dengan survei pendahuluan di Bulan Oktober 2017. Dari hasil survei tersebut, kemudian dilakukan analisis untuk menentukan kebutuhan mitra. Setelah kebutuhan mitra ditentukan, disusun skenario kegiatan serta dipersiapkan segala bahan dan perlengkapan yang akan digunakan untuk kegiatan penyuluhan.

Kegiatan penyuluhan dimulai dengan sambutan dari Ketua RT 007/RW 002 dan Ketua Tim PKM STT-PLN. Setelah itu, dilanjutkan dengan pemaparan materi tentang sampah organik dan anorganik serta demonstrasi pembuatan pupuk kompos dari sampah organik yang disampaikan oleh Tim PKM STT-PLN.

Sebelum kegiatan penyuluhan para warga diberikan pre test untuk mengukur tingkat pemahaman warga terkait materi yang akan disampaikan. Pertanyaan terkait pengertian sampah, jenis-jenis sampah, pengelolaan sampah, dan lain-lain. Hasil tes menunjukan bahwa warga sudah menyadari pentingnya kebersihan namun pengetahuan untuk pengolahan sampah masih sangat minim.

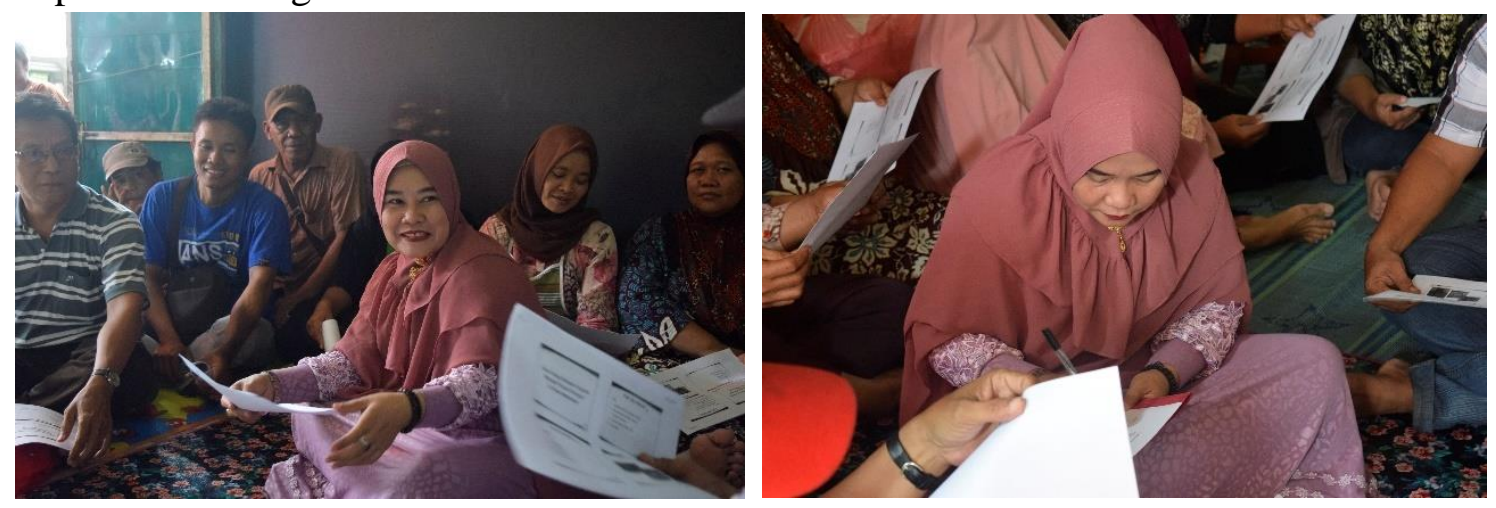

Gambar 1. Pelaksanaan Pre Test

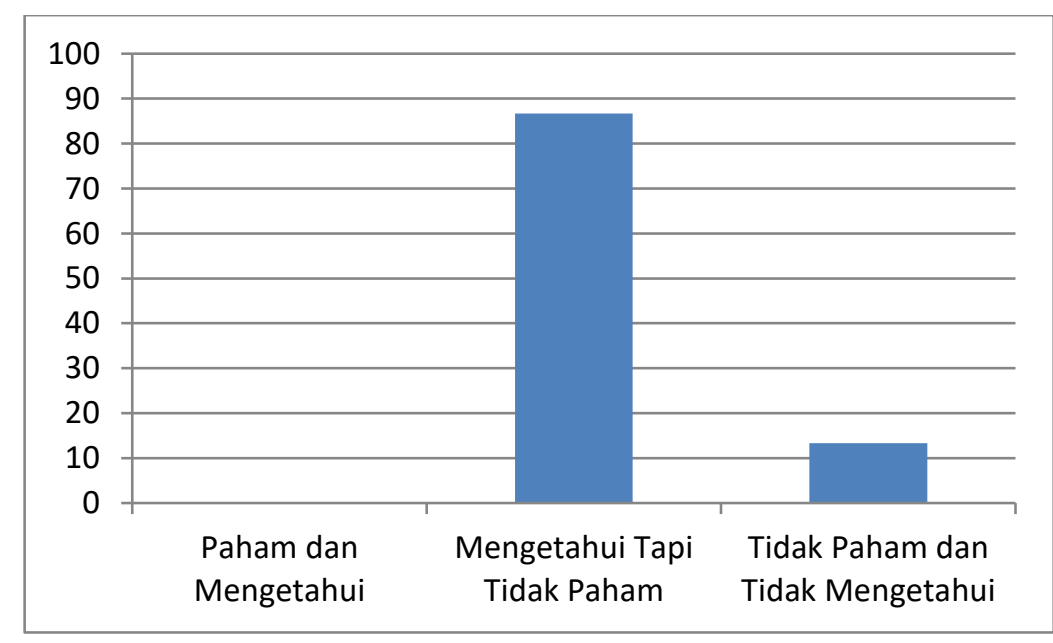

Gambar 2. Persentase Tingkat Pemahaman Warga Tentang Pengolahan Sampah Organik Menjadi Kompos 
Gambar 2 menunjukan bahwa seluruh warga sudah mengetahui bahwa sampah organik yang selama ini mereka buang dapat diolah menjadi pupuk kompos, akan tetapi cara dan prosedur pembuatan pupuk yang masih menjadi kendala. Maka dari itu kegiatan PKM ini dirasa sangat membantu warga dalam menanggulangi sampah organik dan memberi nilai tambah pada sampah organik yang kemudian diolah menjadi pupuk kompos.

Selama kegiatan berlangsung, terlihat antusias peserta yang cukup besar. Hal ini tampak dari semangat para peserta selama sesi paparan dan demonstrasi serta adanya timbal balik dari peserta pada sesi tanya jawab. Kegiatan pemaparan materi sendiri dibagi menjadi 3 sesi, sesi pertama penyampaian materi tentang pengolahan sampah organik menjadi pupuk kompos, sesi kedua simulasi pembuatan pupuk kompos, dan sesi ketiga diskusi serta tanya jawab.
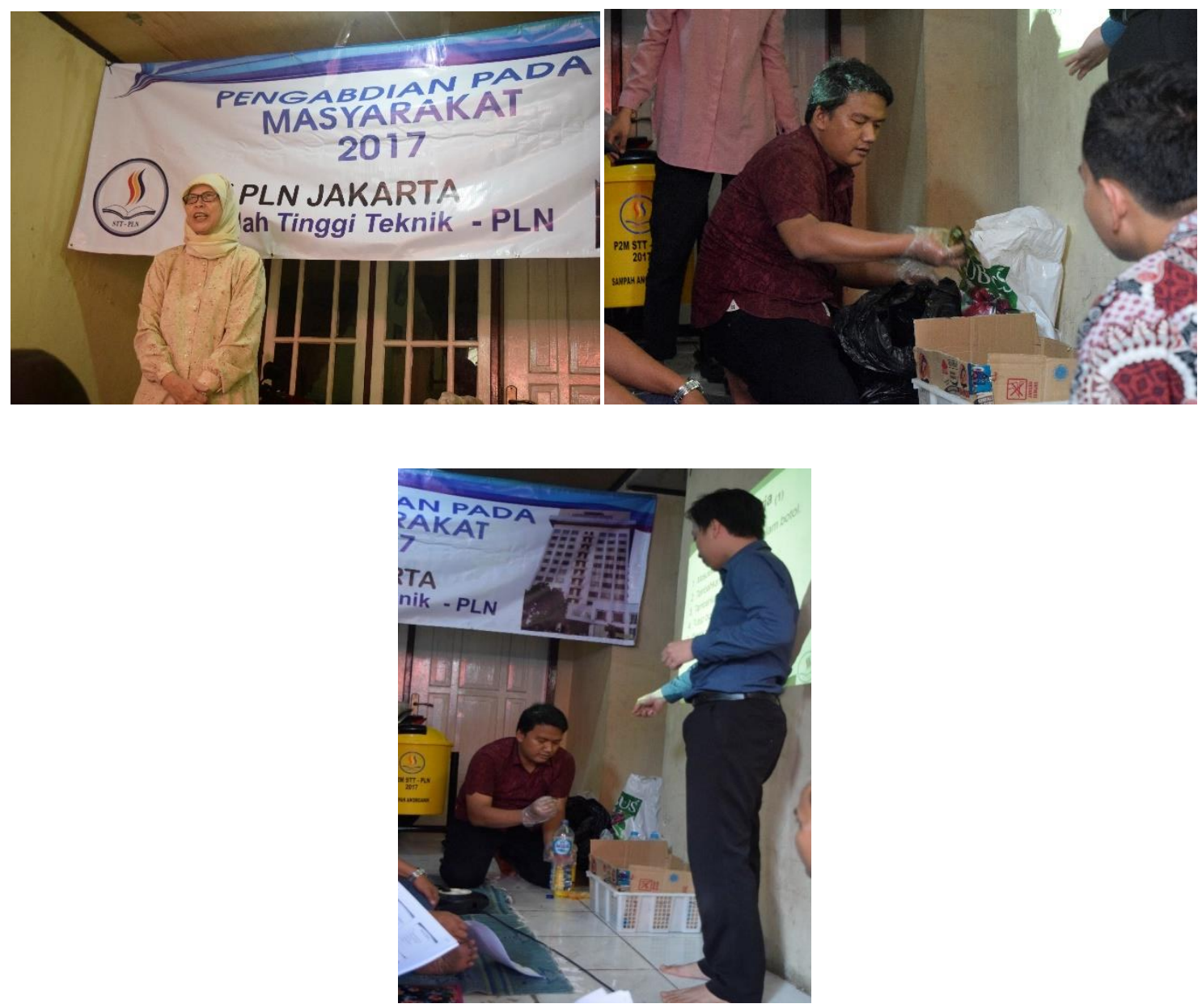

Gambar 3. Penyampaian Materi dan Simulasi Pembuatan Pupuk Organik

Kendala yang dihadapi selama kegiatan penyuluhan adalah terkait dengan tempat terselenggaranya acara. Dikarenakan target penyuluhan adalah masyarakat di sekitar Pasar Madrasah, maka tempat dilakukannya penyuluhan pun berada di lingkungan Pasar 
Madrasah. Kapasitas tempat tersebut kurang dapat menampung animo peserta yang cukup besar, sehingga banyak peserta yang terpaksa berdiri di luar ruangan untuk dapat mengikuti kegiatan penyuluhan.

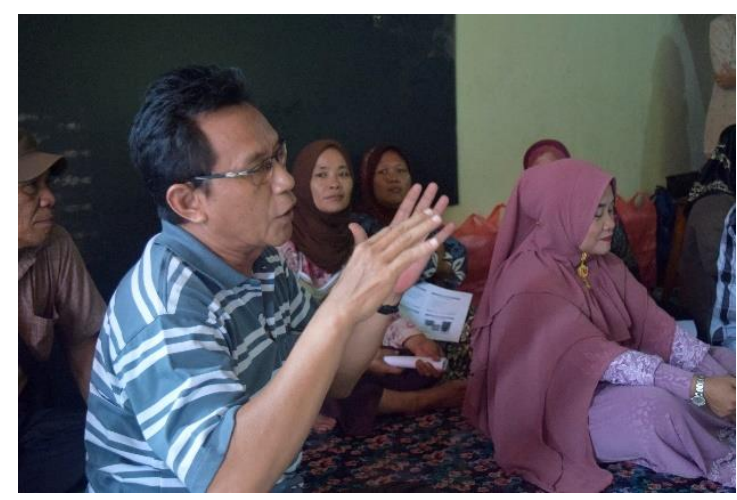

Gambar 4. Dialog dan Diskusi dengan Warga

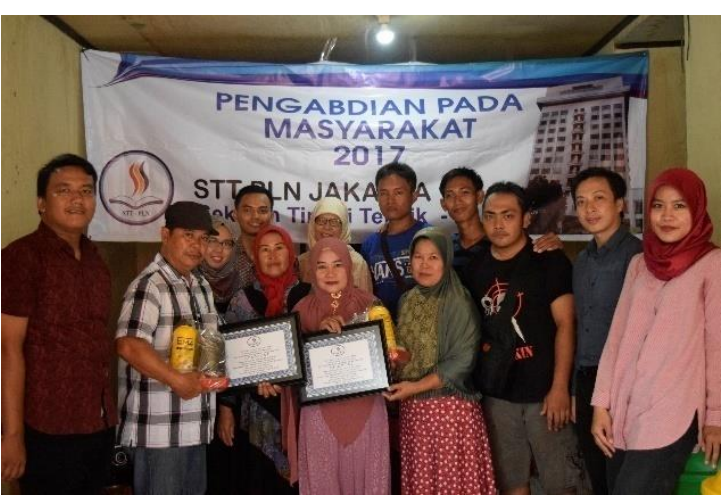

Gambar 5. Foto Bersama Peserta Kegiatan

Setelah acara selesai tim PKM juga memberikan sepasang tempat sampah yang difungsikan untuk tempat sampah organik dan anorganik sehingga memudahkan warga dalam memilah jenis sampah sehingga lebih mudah untuk proses pengolahan sampah organik menjadi pupuk kompos, serta lingkungan sekitar menjadi lebih bersih dan nyaman.

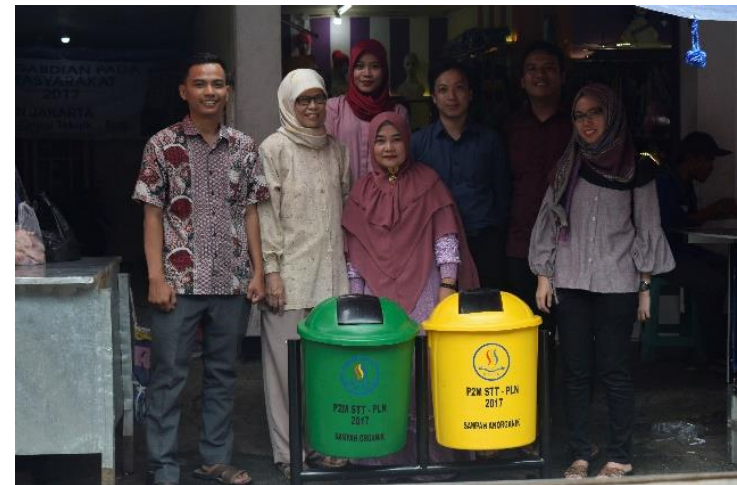

Gambar 5. Foto Bersama Peserta Kegiatan 
Secara umum, kegiatan penyuluhan yang dilakukan oleh Tim PKM STT-PLN ini dapat terselenggara dengan baik dan lancar. Ketua RT setempat mendukung penuh kegiatan penyuluhan ini. Masyarakatnya pun banyak membantu Tim dalam mempersiapkan kegiatan. Selain itu, semua peserta juga aktif dan antusias selama kegiatan berlangsung.

\section{KESIMPULAN}

Sistem pengelolaan sampah rumah tangga berbasis masyarakat dengan prinsip $3 \mathrm{R}$ melalui kegiatan pemilahan sampah merupakan solusi paradigmatik, yaitu solusi dari paradigma cara mengelola sampah. Dari paradigma "membuang sampah" yang dalam prakteknya hanya memindahan sampah, menjadi "mengelola sampah" dalam arti memilah untuk dimanfaatkan yang pada prakteknya dapat mereduksi secara signifikan timbulan sampah yang dibuang. Problematika utama dari penerapan model ini adalah pada soal bagaimana merubah paradigma dari membuang sampah menjadi memanfaatkan sampah. Peran pengurus RT/RW sangat besar dalam membantu mewujudkan terlaksananya program dan menjembatani komunikasi antara pemerintah daerah dengan masyarakat ${ }^{[4]}$.

Setelah kegiatan penyuluhan terlaksana, beberapa hal yang dapat dicapai adalah:

1. Peserta paham akan pentingnya menjaga kebersihan lingkungan sekitar.

2. Peserta paham akan perbedaan sampah organik dan anorganik serta dapat memilah sampah terlebih dahulu sebelum dibuang pada tempatnya.

3. Peserta mengerti bahwa sampah organik dapat diolah menjadi pupuk kompos serta paham cara mengolahnya.

4. Sampah organik yang awalnya terbuang begitu saja, menjadi memiliki nilai tambah dan berdaya guna setelah diolah menjadi pupuk kompos.

\section{SARAN}

Selama kegiatan penyuluhan berlangsung hingga selesai ditemukan beberapa permasalahan yang menghambat kegiatan tersebut dan harapan yang belum tercapai. Adapun saran untuk kegiatan selanjutnya adalah:

1. Diharapkan kegiatan serupa dapat sering diadakan khususnya di lingkungan sekitar kampus STT-PLN, mengingat masih cukup banyaknya wilayah yang terbilang kotor dan menghasilkan sampah yang cukup banyak.

2. Adanya kelanjutan kegiatan, dengan fokus bukan hanya pada pengolahan sampah organik saja namun juga pengolahan sampah anorganik.

3. Adanya kegiatan penyuluhan mengenai penanganan limbah B3, mengingat cukup banyaknya klinik kesehatan di sekitar kampus STT-PLN

\section{UCAPAN TERIMA KASIH}

Penulis mengucapkan terima kasih kepada STT PLN dan warga masyarakat, perangkat kelurahan serta tokoh masyarakat di wilayah RT 007 dan RT 012/RW 02 Kelurahan Duri Kosambi,Kecamatan Cengkareng, Jakarta Barat, serta seluruh pihak yang telah memberi dukungan dan membantu pelaksanaan kegiatan pengabdian pada masyarakat. 


\section{DAFTAR PUSTAKA}

[1] Peraturan Menteri Pekerjaan Umum Nomor: 21/PRT/M/2006

[2] Undang-Undang Republik Indonesia Nomor 18 Tahun 2008 tentang Pengelolaan Sampah.

[3] http://ensiklo.com/2014/07/27/mengolah-sampah-organik-menjadi-kompos/ diakses tanggal 18 Februari 2017

[4] Faizah, 2008, Pengelolaan Sampah Rumah Tangga Berbasis Masyarakat (Studi Kasus di Kota Yogyakarta), Tesis Program Magister Ilmu Lingkungan Program Pasca Sarjana Universitas Diponegoro, Semarang 